\title{
Penilaian Keberhasilan Reklamasi Pada Pit Serujan Utara PT. IMK
}

\section{Kabupaten Murung Raya \\ (Assessment of The Reclamation Success At The Northern Serujan Pit in PT. IMK Murung Raya Regency)}

\author{
Fahrul Indrajaya ${ }^{1 *}$, Marlen Fince T. L. ${ }^{2}$, Neny Fidayanti ${ }^{3}$, Yossa Yonathan Hutajulu ${ }^{4}$ \\ ${ }_{1,2,3,4}$ Jurusan/Program Studi Teknik Pertambangan, Universitas Palangka Raya \\ * Korespondensi E-mail : fahrulindrajaya@mining.upr.ac.id
}

\begin{abstract}
Abstrak
PT. IMK terletak di Kabupaten Murung Raya Provinsi Kalimantan Tengah yang bergerak di bidang penambangan emas dan perak dengan luas kontrak 47,940 hektar. Penelitian ini bertujuan untuk menilai kegiatan reklamasi yang telah dilakukan di Pit Serujan Utara. Pelaksanaan reklamasi di PT. IMK diawali dengan pendekatan berdasarkan Keputusan Menteri Energi dan Sumber Daya Mineral Nomor: 1827 K/30/MEM/2018 tentang Pedoman Regulasi Teknik Pertambangan yang baik. Parameter yang digunakan dalam menilai keberhasilan reklamasi adalah pemanfaatan lahan, revegetasi, dan penyelesaian akhir. Berdasarkan hasil kriteria penilaian reklamasi yang dilakukan pada Pit Serujan Utara diperoleh dengan total nilai $93,33 \%$, kategori yang baik (hasil reklamasi dapat diterima).
\end{abstract}

Kata kunci: Penilaian reklamasi, kriteria sukses, pit serujan

\begin{abstract}
PT. IMK is located in Murung Raya Regency, Central Kalimantan province, which is engaged in gold and silver mining with an area of 47.940 hectares contract. This research aims to assess the reclamation activities that have been done in the Northern Serujan Pit. The implementation of reclamation in PT. IMK begins with the approach based on the decree of the Minister of Energy and Mineral Resources number: 1827 K/30/MEM/2018 on the guidelines of good mining technical regulations. The parameters used in assessing the success of reclamation are land utilization, revegetation, and final settlement. Based on the results of the reclamation assessment criteria carried out on the Northern Serujan Pit is obtained by total value of $93.33 \%$, a good category (reclamation results are acceptable).
\end{abstract}

Keywords: Reclamation assessment, success criteria, serujan pit

\section{Pendahuluan}

Kegiatan penggalian bahan tambang pasti selalu merubah rona awal lingkungan, terutama pada vegetasi dan morfologi yang apabila tidak ditangani dengan baik akan meninggalkan lubang bekas galian tambang yang akhirnya menjadi void.

PT. IMK merupakan suatu perusahaan yang bergerak dibidang usaha pertambangan emas dan perak dengan area kontrak karya seluas $47.940 \mathrm{Ha}$. Adapun area yang akan dilakukan penatagunaan lahan seluas $4,4 \mathrm{Ha}$ dan kegiatan revegetasi seluas $4,3 \mathrm{Ha}$.

Penilaian kriteria keberhasilan reklamasi merujuk pada Keputusan Menteri ESDM Nomor: 1827 Tahun 2018 yang terdiri dari kriteria tingkat keberhasilan reklamasi untuk operasi produksi dan pedoman penilaian reklamasi untuk operasi produksi dan Undang-Undang No. 26 Tahun 2018 tentang pelaksanaan kaidah pertambangan yang baik, dan Permenhut No. P.60/MenhutII/2009 tentang pedoman penilaian keberhasilan reklamasi hutan. Berdasarkan aturan tersebut ada beberapa tahapan yang dilakukan, yaitu penanganan tanah pucuk, penataan lahan, penebaran tanah pucuk, persemaian bibit, revegetasi dan pemeliharaan.

\section{Metode}

Lokasi penelitian berada pada lokasi tambang emas dan perak PT. IMK yang berada sekitar $\pm 70 \mathrm{~km}$ disebelah selatan Katulistiwa, dimana pusatnya terletak pada titik koordinat 00 38'32" Lintang Utara dan 114'24'14" Bujur Timur yang terletak di Kecamatan Tanah Siang Selatan, Kabupaten Murung Raya, Provinsi Kalimantan Tengah.

Berdasarkan peta kesampaian daerah bahwa untuk menuju ke lokasi penelitian menggunakan 2 (dua) alternatif, yaitu jalur darat 
dan jalur udara. Waktu tempuh kurang lebih 10 jam menggunakan roda empat dan 40 menit menggunakan jalur udara dari Kota Palangka Raya (Gambar 2).

Penelitian ini dilakukan secara pendekatan kuantitatif deskriptif. Pemakaian metode kuantitatif deskriptif ini disesuaikan dengan variabel pada matrik kriteria keberhasilan penilaian reklamasi.

Dalam pengolahan data menggunakan skoring dan pembobotan serta membandingkan dengan Keputusan Menteri ESDM Nomor: 1827 Tahun 2018. Setelah penilaian terhadap keberhasilan evaluasi reklamasi berdasarkan data dilapangan, maka dapat menggunakan rumus yang berdasarkan pada pedoman evaluasi tingkat keberhasilan reklamasi hutan dari Direktorat Jenderal Rehabilitasi Lahan dan Perhutanan (2009) sebagai berikut:

$$
T N=\sum_{=1}^{n}\left[\frac{T S}{S M} \times \text { Bobot }\right] \text {. }
$$

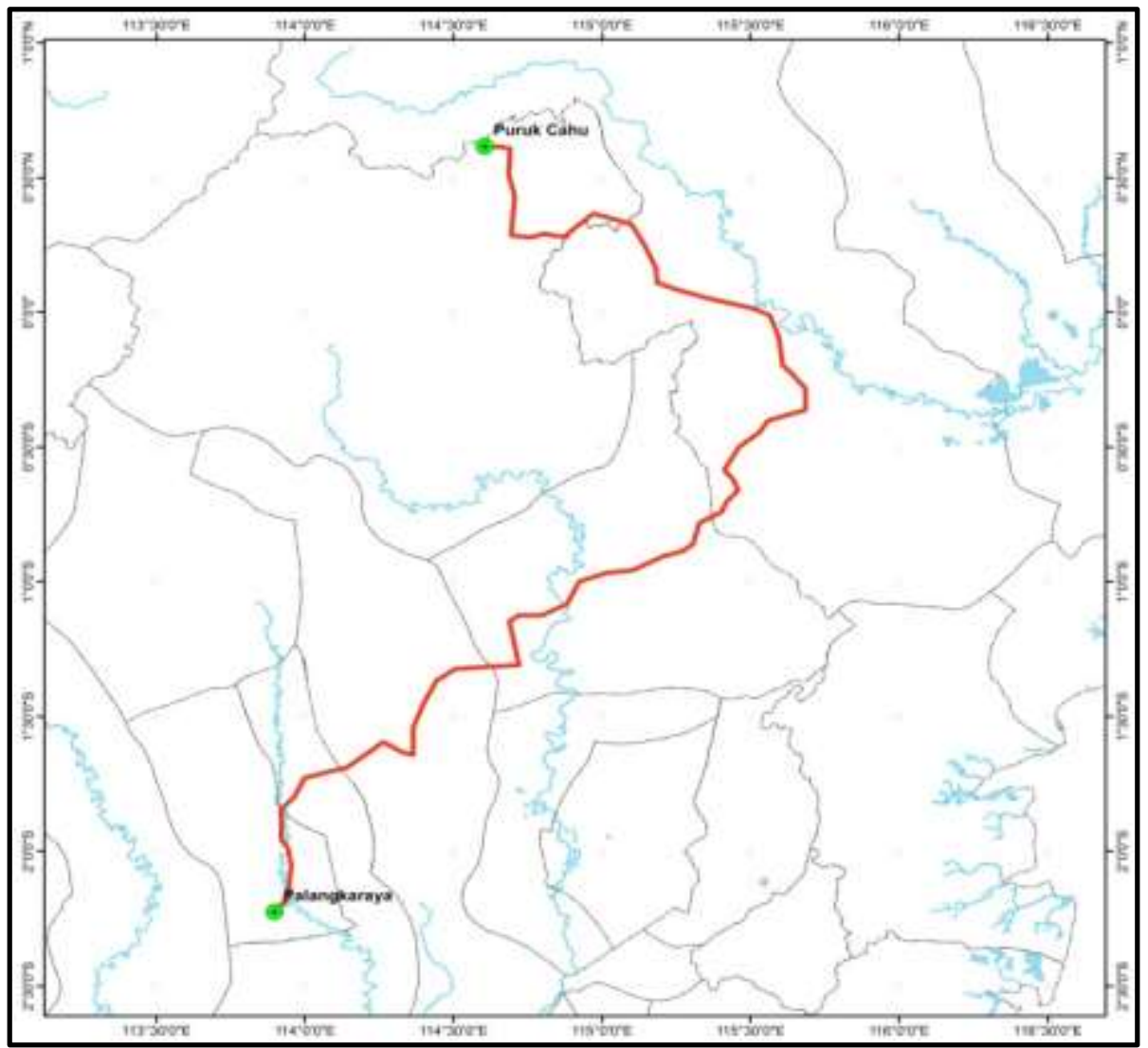

Gambar 1. Lokasi Penelitian

\section{Keterangan :}

Total nilai evaluasi $=$ TN

Total skor evaluasi masing-masing kriteria = TS Nilai maksimal tiap kriteria $=\mathrm{SM}$ Jumlah Kriteria $=\mathrm{N}$

\section{Hasil dan Pembahasan}

Kegiatan reklamasi yang telah dilaksanakan pada area Pit Serujan Utara dengan luas area reklamasi yaitu 4,4 $\mathrm{Ha}$. Kriteria keberhasilan reklamasi dilakukan, yaitu :

1) Penatagunaan Lahan.

a. Penataan lahan dari rencana area yang ditata seluas $4,4 \mathrm{Ha}$ terealisasi seluas $4,3 \mathrm{Ha}$ atau sebesar $97,72 \%$ dan stabilitas timbunan dari yang terlihat tidak terjadi longsor (Gambar 2). Adapun perhitungan skor dan bobot ialah 40 . Penimbunan kembali pada lahan bekas tambang emas pada area reklamasi menggunakan metode backfilling. Hasil penilaian luas area yang ditimbun pada objek kegiatan penimbunan kembali lahan bekas tambang adalah 97,72\% dan tidak mencapai $100 \%$ dikarenakan kurangnya tanah yang berada pada bank soil.

b. Penebaran tanah zona pengakaran dari rencana areal yang ditata seluas 4,4 Ha terealisasi seluas $4,3 \mathrm{Ha}$ atau sebesar $97,72 \%$ dan $\mathrm{pH}$ tanah 7 . Adapun perhitungan skor dan bobot ialah 10 . 


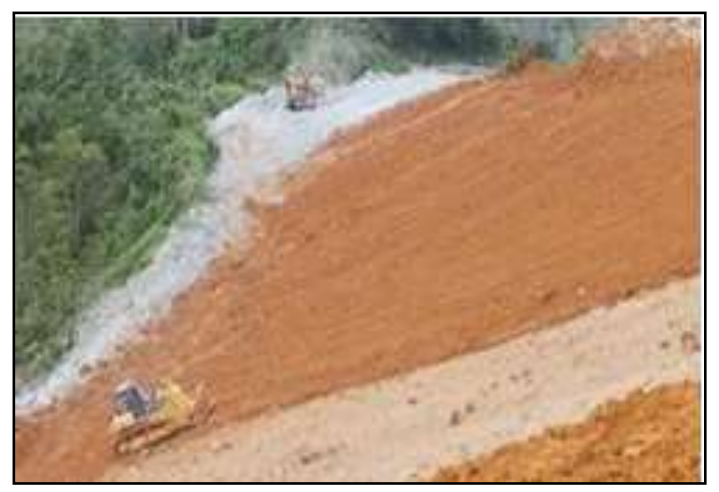

Gambar 2. Penataan Lahan Area Pit Serujan

Pada area reklamasi Pit Serujan Utara dengan ketebalan tanah pucuk (soil) $50 \mathrm{~cm}$ dengan kemiringan $30^{\circ}$. Dengan hasil $\mathrm{pH}$ tanah 7 (bersifat basa), jadi tidak perlu dilakukan penanganan atau pengendalian seperti pengapuran pada tanah masam untuk menaikkan $\mathrm{pH}$ tanah.

c. Pengendalian erosi dan sedimentasi serta pengelolaan air dibuat sesuai dengan rencana pada saluran terbuka (drainase). Hasil pengamatan dilapangan tidak terdapat bangunan pengendali erosi dibuat. Adapun perhitungan skor dan bobot ialah 5 .

d. Pengaturan SPA yang ada dilapangan sesuai dengan aturan Permenhut No. P.4/Menhut-II/
2011 yakni berbentuk penampang trapesium dan masih berfungsi. Sedangkan untuk pengelolaan kualitas air yang keluar dari areal penggunaan kawasan hutan yang telah dilakukan seperti penyaliran air ke badan sungai harus sesuai dengan peraturan, yakni Kepmen Lingkungan Hidup Nomor 202 Tahun 2004 dengan dilakukan pengecekan setiap harinya minimal untuk parameter $\mathrm{pH}$ air.

2) Revegetasi

a. Luas area penanaman dan pertumbuhan tanaman telah dibuat sesuai rencana (Gambar 3). Adapun hasil perhitungan skor dan bobotnya ialah 15 .

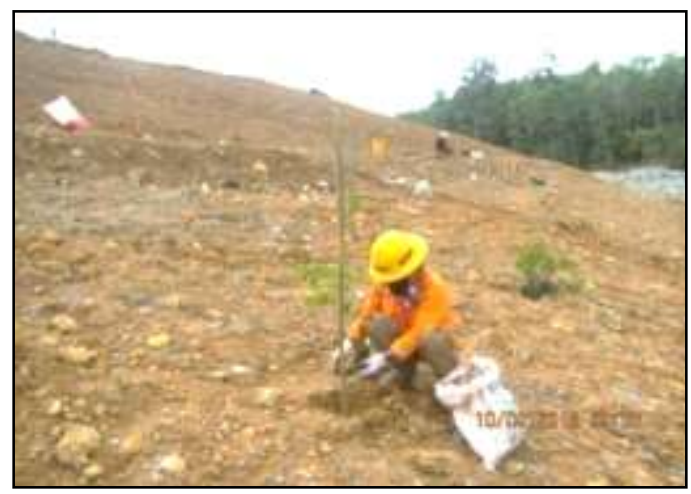

Gambar 3. Kegiatan Revegetasi

Tanaman yang sudah ditanam per hektar diterapkan dengan metode tanam maksimal 4 meter x 4 meter, sehingga jumlah pohon per hektar sebanyak 625 pohon. Oleh karena itu perhitungan diambil dari data jumlah pionir mengingat jarak tanam pionir yang ditetapkan perusahaan ialah $4 \mathrm{~m}$ x $4 \mathrm{~m}$ sedangkan sisipan $8 \mathrm{~m} \times 4 \mathrm{~m}$.

Perlunya penanaman pionir dilakukan pada area yang mungkin untuk ditanam pada area yang kurang jumlah pionir agar tercapainya jumlah tanaman yang seharusnya agar dapat memberikan fungsi maksimal seperti naungan yang cukup bagi tanaman sisipan.
Berdasarkan dokumen rencana reklamasi tambang (RPT) PT. IMK, rencana tata guna lahan menjadi hutan produksi konversi (HPK) atau kawasan hutan yang secara ruang dicadangkan bagi pembangunan diluar kehutanan. Hasil kegiatan pemantauan yang dilakukan serta evaluasi dilapangan menunjukkan nilai pertumbuhan atau kesehatan di setiap area dikategorikan baik (>90\%). Hal ini juga menunjukan jenis tanaman yang dipilih memiliki kemampuan hidup yang baik dilokasi reklamasi tambang.

Meskipun memiliki nilai yang baik namun juga masih terdapat tanaman sakit bahkan merana 
pada setiap area reklamasi. Tanaman yang ditemukan menunjukan ciri seperti daun yang berwarna kuning, bercak merah kecoklatan seperti terbakar, kering di area daun, daun berlubang, berbintil, mengerucut, dan batang bengkok. Sedangkan tanaman merana disebabkan tanaman yang roboh, kerdil, daun habis gugur, batang utama patah serta batang yang berbintil.

Kondisi tersebut cukup rentan terdapat pada tanaman muda atau tanaman sisipan. Sedangkan tanaman lama ataupun juga tanaman pionir lebih kerdil, batang patah, dan roboh.

b. Pengelolaan material pembangkit air asam tambang dibuat sesuai rencana pada pengelolaan terhadap material serta kolam pengendapan sedimen. Bangunan pengendali erosi tidak dibuat. Adapun perhitungan skor dan bobot ialah 3,33.

c. Untuk mengetahui adanya potensi material pembangkit air asam tambang dilakukan penelitian pada batuan sulfida yang kaya akan pyrit atau disebut material PAF (Potential Acid Forming). Selanjutnya dilakukan enkapsulasi dengan cara material PAF akan ditimbun dengan material NAF dan dilapisi dengan top soil saat kegiatan penataan lahan.

Berdasarkan data kualitas air yang didapat selama tahun 2017 - 2018, rata-rata pH air di SRJ-01 (Settling Pond) adalah 7,87. Nilai pH air tergolong normal atau baik dan sesuai dengan Baku Mutu Lingkungan (BML).

3) Penyelesaian akhir

a. Penutupan tajuk merupakan keseluruhan bagian tumbuhan, terutama pohon yang berada diatas permukaan tanah yang melingkupi suatu area. Penutupan tajuk dibuat sesuai rencana. Adapun perhitungan skor dan bobotnya ialah 10 .

b. Pemeliharaan tanaman dibuat sesuai rencana. Adapun perhitungan skor dan bobotnya ialah 10 .

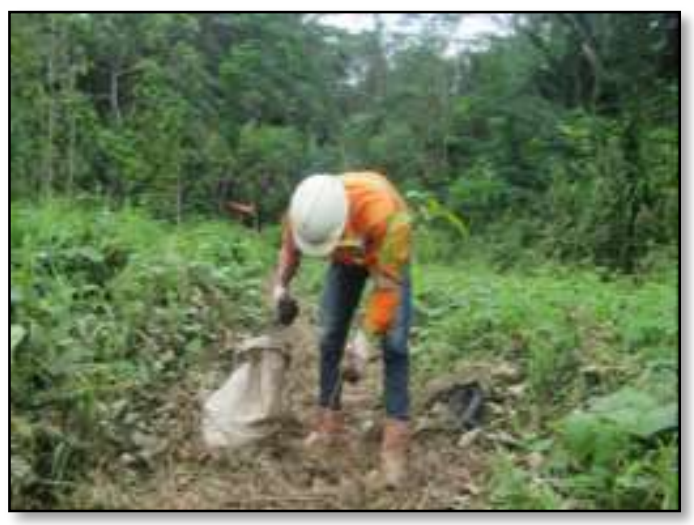

Gambar 4. Kegiatan Pemupukan

c. Kegiatan yang telah dijalankan oleh PT. IMK ialah pupuk kompos dan pupuk NPK. Sehingga nilai evaluasi pemupukan adalah $100 \%$ karena sesuai dengan yang telah direncanakan.

Pada kegiatan pengendalian gulma, kegiatan ini dilakukan pada area yang baru saja ditanami bibit dan umur maksimal tanaman yang dilakukan pengendalian gulma adalah 3 (tiga) bulan setelah penanaman, agar tidak terjadi proses persaingan dan pertumbuhan tanaman. Pada PT. IMK dilakukan penanganan terhadap gulma di area tanam reklamasi dengan cara manual/penyiangan. Penyulaman dilakukan sesuai dengan rencana yaitu menggantikan tanaman yang mati dengan tanaman yang baru. Hal yang menyebabkan tanaman mati pada area reklamasi dikarenakan musim kemarau panjang, tertutup gulma dan terlilit tanaman penutup.

Setelah dilakukan skoring dan pembobotan pada kriteria penilaian berdasarkan Keputusan Menteri ESDM Nomor: 1827 Tahun 2018, maka dapat dilihat pada grafik penilaian reklamasi pada area Pit Serujan Utara (Gambar 5).

Berdasarkan hasil penilaian keberhasilan reklamasi pada area Pit Serujan Utara dengan merujuk pada Keputusan Menteri ESDM Nomor: 1827 Tahun 2018, yaitu dengan nilai 93,33\% (kategori baik) sehingga hasil pelaksanaan reklamasi dapat diterima (Tabel 1). Kriteria ketidak-berhasilan reklamasi yang terjadi yaitu pengendalian erosi dan sedimentasi dan pengelolaan material pembangkit air asam tambang (AAT). 
Tabel 1. Bobot dan Penilaian Reklamasi Operasi Produksi Area Pit Serujan Utara

\begin{tabular}{|c|c|c|c|}
\hline No & Kegiatan & Bobot $(\%)$ & Nilai (\%) \\
\hline \multirow[t]{4}{*}{1.} & Penatagunaan Lahan & & \\
\hline & - Penataan Lahan dan Penimbunan & 40 & 40 \\
\hline & - Penebaran Tanah Pucuk (top soil) & 10 & 10 \\
\hline & - Pengendalian Erosi dan Sedimentasi & 10 & 5 \\
\hline \multirow[t]{3}{*}{2.} & Revegetasi & & \\
\hline & $\begin{array}{l}\text { a. Luas Tanaman dan Tingkat } \\
\text { Pertumbuhan }\end{array}$ & 15 & 15 \\
\hline & $\begin{array}{l}\text { b. Pengelolaan material pembangkit } \\
\text { Asam Tambang }\end{array}$ & 5 & 3,33 \\
\hline \multirow[t]{4}{*}{3.} & Penyelesaian Akhir & & \\
\hline & a. Penutupan Tajuk & 10 & 10 \\
\hline & b. Pemeliharaan Tanaman & 10 & 10 \\
\hline & Total & 100 & 93,33 \\
\hline
\end{tabular}

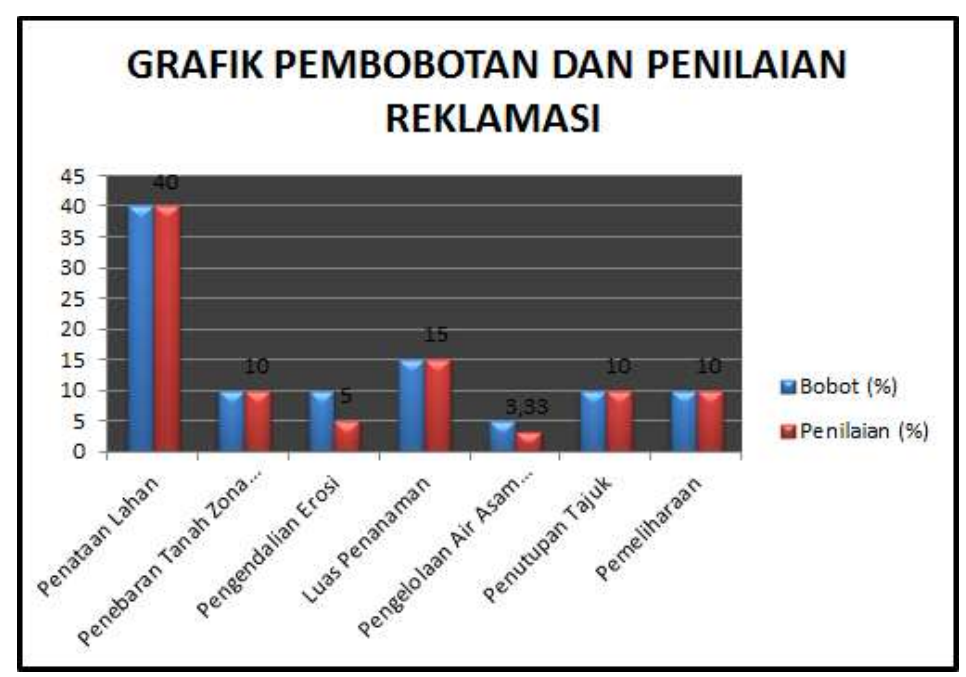

Gambar 5. Perbandingan nilai reklamasi tambang di daerah penelitian dibandingkan dengan nilai reklamasi berdasarkan Kepmen No. 1827 Tahun 2018.

\section{Kesimpulan}

PT. IMK telah berhasil melakukan kegiatan reklamasi tambang dengan kategori baik yaitu $93,33 \%$ yang berkisar lebih dari $80 \%$ (hasil pelaksanaan reklamasi dapat diterima, dengan beberapa evaluasi yang harus dilakukan, yaitu pengendalian erosi dan sedimentasi serta pengelolaan material pembangkit asam tambang (AAT). Pada bank soil seharusnya dimaksimalkan penggunaannya dan juga untuk persiapan tanah pucuknya agar tidak terjadi kekurangan dalam penebaran tanah pucuk. Sebaiknya dibuat bangunan pengendali erosi berupa teras bangku karena sesuai dengan kelerengan yang ada.

\section{Ucapan Terimakasih}

Peneliti turut mengucapkan terima kasih sebesarbesarnya kepada pihak PT. IMK yang telah mengizinkan untuk melakukan pengambilan data dilapangan dan sebagian pihak yang terlibat dalam penelitian ini.

\section{Daftar Pustaka}

Afriani, Kristi., 2019. Evaluasi Tingkat Keberhasilan Reklamasi Pada Lahan Bekas Penimbunan PT. Kasongan Bumi Kencana Desa Mirah Kalanaman Kecamatan Katingan Tengah Kabupaten Katingan Provinsi Kalimantan Tengah. Program Studi Teknik Pertambangan Universitas Palangka Raya.

Departemen Enviromental., 2019. Daftar Nama Tanaman Pada Area Reklamasi Pit Serujan Utara. PT. Indo Muro Kencana, Kalimantan Tengah. 
Guskarnali, G., Parenty, R. K., \& Andini, D. E., 2019. Analisis Keberhasilan Reklamasi berdasarkan Keputusan Menteri Energi dan Sumber Daya Mineral Nomor 1827 Tahun 2018 pada Lahan Bekas Tambang Air Jelitik 3 PT TIMAH Tbk Kabupaten Bangka. MINERAL, 4(2), 72-77 pp.

Hardjowigeno, 1987. Kriteria Penilaian Sifat Kimia Tanah. Jakarta.

Indrajaya, F., 2016. Studi Pengelolaan Kualitas Air Pada Lubang Bekas Tambang (Void) Pasir Urug dan Pasir Pasang Di Kecamatan Sebangau Kota Palangka Raya Provinsi Kalimantan Tengah (Doctoral dissertation, UPN" Veteran" Yogyakarta).

Keputusan Menteri Energi Sumber Daya Manusia (ESDM) No. 26 Tahun 2018 Tentang Pedoman Pelaksanaan Kaidah Teknik Pertambangan Yang Baik. Jakarta.

Keputusan Menteri Energi dan Sumber Daya Mineral Republik Indonesia Nomor 1827 K/30/MEM/2018 Tentang Pedoman Pelaksanaan Kaidah Teknik Pertambangan yang Baik. Jakarta.

Nugroho, A. W., \& Yassir, I., 2017. Kebijakan Penilaian Keberhasilan Reklamasi Lahan Pasca-Tambang Batubara Di Indonesia Policy Study on Post Coal Mining Reclamation Assessment in Indonesia. Jurnal Analisis Kebijakan Kehutanan, 14 (2), 121-136 pp.

Peraturan Menteri Kehutanan Republik Indonesia No P.60/Menhut-II/2009 tentang Pedoman Penilaian Keberhasilan Reklamasi Hutan.
Peraturan Menteri Kehutanan Republik Indonesia No P.4/Menhut-II/2011 tentang Pedoman Reklamasi Hutan. Jakarta.

Peraturan Menteri Lingkungan Hidup Dan Kehutanan Republik Indonesia Nomor: P.51/Menlhk/Setjen/Kum.1/6/2016 Tentang Tata Cara Pelepasan Kawasan Hutan Produksi Yang Dapat Dikonversi. Jakarta.

Portasya, R., Handayani, R. H. E., \& Syarifuddin, S., 2019. Evaluasi Tingkat Keberhasilan Penatagunaan Lahan, Revegetasi Dan Penyelesaian Akhir Dalam Kegiatan Reklamasi Di Area Backfilling Pit 3 Timur PT. Bukit Asam TBK. Tanjung Enim, Sumatera Selatan (Doctoral dissertation, Sriwijaya University).

Putri, A. P., Widayati, S., \& Usman, D. N., 2019. Kajian Penilaian Keberhasilan Reklamasi Lahan Bekas Penambangan Batubara di PT Madhani Talatah Nusantara, Desa Rantau Nangka, Kecamatan Sungai Pinang, Kabupaten Banjar, Provinsi Kalimantan Selatan.

Tauran, I. L., 2015. Evaluasi Keberhasilan Reklamasi Pada Lahan Pasca Tambang Di Pit Grasberg PT. Freeport Indonesia Kecamatan Tembagapura Kab Mimika Papua (Doctoral dissertation, UPN" Veteran" Yogyakarta).

Yassir, I., 2017. Kebijakan Penilaian Keberhasilan Reklamasi Lahan Pasca-tambang Batubara di Indonesia. Jurnal Analisis Kebijakan Kehutanan, 14 (2), 121-136 pp. 